\title{
A FORMA URBANA A PARTIR DE PLANOS DIRETORES E LEIS DE ZONEAMENTO DO MUNICÍPIO DE SÃO PAULO
}

\section{THE URBAN FORM FROM DIRECTOR PLANS AND ZONING LAWS OF THE MUNICIPALITY OF SÃO PAULO}

\author{
Kazuo Nakano ${ }^{1}$ \\ FIAM-FAAM Centro Universitário, São Paulo, SP, Brasil, kazuo.nakano@gmail.com \\ Sully Alonso Guatella ${ }^{2}$ \\ FIAM-FAAM Centro Universitário, São Paulo, SP, Brasil, sullyalonso@gmail.com
}

\section{Resumo}

Há tempos os instrumentos de planejamento e regulação urbana utilizados no Brasil deixaram de considerar os efeitos espaciais e as formas urbanas produzidas pela implementação de seus parâmetros de parcelamento, uso e ocupação do solo. Poucos estudos se debruçaram sobre os tipos e formas de espaços urbanos produzidos a partir dos regramentos estabelecidos por planos diretores e leis de zoneamento. O presente artigo chama a atenção para a importância e necessidade de estudos dessa natureza ao discutir as relações entre mecanismos e parâmetros de regulação do parcelamento, uso e ocupação do solo e formas urbanas no contexto do Município de São Paulo. Assim, inicia com um panorama geral sobre essa relação a partir de estudos sobre o "zoning" norteamericano que influenciou fortemente o zoneamento paulistano. Em seguida apresenta e analisa aspectos relativos à relação entre parâmetros de ocupação do solo e a produção de empreendimentos imobiliários verticais presentes na Lei Geral de Zoneamento do Município de São Paulo de 1972 e nos Planos Diretores Estratégicos do Município de São Paulo de 2002 e 2014. Esse último Plano Diretor, sancionado recentemente, incluiu mecanismos e parâmetros de regulação da ocupação do solo paulistano com a intenção explícita de induzir a geração de formas urbanas com maior interação entre espaços públicos e privados, edificações e calçadas, quadras e ruas.

Palavras-chave: Forma urbana. Uso e ocupação do solo.

\begin{abstract}
For some time the planning and urban regulation instruments used in Brazil failed to consider the spatial effects and urban forms produced by the implementation of its parameters. Few studies have looked into the types and forms of urban spaces produced from the urban legislation established by master plans and zoning laws. This article draws attention to the importance and need for such studies to discuss the relationship between parameters of land regulation and urban forms in the context of São Paulo Municipality. Thus, begins with an overview of this relationship from studies about "zoning" used in the USA which strongly influenced the São Paulo zoning law since the beginning of the twentieth century. Then it presents and analyzes aspects of the relationship between land regulation parameters and the urban form of the vertical buildings produced by the real estate agents based on the Zoning General Law of 1972 and Strategic Directors Plans of 2002 and 2014. The latter Director Plan, recently sanctioned, included mechanisms and land regulatory parameters to induce, intentionally, the generation of certain urban forms which intensify interactions between the public and private spaces, buildings and sidewalks, blocks and streets.
\end{abstract}

Keywords: Urban form. Land use and occupation.

How to cite this article:

NAKANO, Kazuo; GUATELLA, Sully Alonso. A forma urbana a partir de planos diretores e leis de zoneamento do Município de São Paulo. PARC Pesquisa em Arquitetura e Construção, Campinas, SP, v. 6, n. 3, p. 142-154, set. 2015. ISSN 1980-6809. Disponível em: <http://periodicos.sbu.unicamp.br/ojs/index.php/parc/article/view/8640799>. Acesso em: 09 mar. 2016. doi:http://dx.doi.org/10.20396/parc.v6i3.8640799. 


\section{Introdução}

Enquanto os esforços para o aperfeiçoamento dos Planos Diretores são levados a cabo a partir da aprovação da Lei Federal 10,257/2001, o Estatuto da Cidade, não se percebe, no Brasil, a existência de esforços similares direcionados para a reformulação das leis de uso e ocupação do solo, mais conhecidas como leis de zoneamento. $\mathrm{O}$ estudo sobre as formas urbanas geradas pelas aplicações de parâmetros de parcelamento, uso e ocupação do solo, previstas em planos diretores e leis de zoneamento, apresenta-se como um caminho importante e bastante fértil para orientar a reformulação e o aperfeiçoamento daquelas leis de zoneamento. Tais leis encontram-se instituídas em mais da metade dos municípios brasileiros. De acordo com a Pesquisa de Informações Básicas Municipais do IBGE de 2013 (IBGE, 2014), dentre os 5.570 municípios brasileiros, $3.021(54,2 \%)$ possuíam legislação sobre zoneamento ou uso e ocupação do solo. Destes últimos municípios, 1.742 $(57,73 \%)$ regulavam o uso e ocupação do solo por meio de lei específica e 1.279 (42,3\%) tinham essa lei específica integrada ao Plano Diretor.

$\mathrm{Na}$ Tabela 1, observa-se a distribuição desses municípios com legislação sobre zoneamento ou uso e ocupação do solo segundo seu porte populacional. Como era de se esperar, mais de $90 \%$ dos municípios médios e grandes, com mais de 100 mil habitantes, tinha aquele tipo de legislação. Nesses municípios, de modo geral, a administração pública é mais bem estruturada e os processos de produção imobiliária e de espaços urbanos são mais intensos e conflituosos gerando maiores impactos, expansões e transformações nas cidades. A regulação do uso e ocupação do solo torna-se mais importante nesses contextos.

Ainda na Tabela 1 é interessante observar que dentre os 1.080 municípios com população entre 20 mil e $50 \mathrm{mil}$ habitantes, $433(40,1 \%)$ tinham legislação sobre zoneamento e uso e ocupação do solo como parte integrante do Plano Diretor. Dentre os 339 municípios com população entre 50 mil e 100 mil habitantes, 146 (44\%) apresentavam a mesma condição. Dentre os municípios médios com população entre 100 mil e 500 mil habitantes, $111(42,7 \%)$ também apresentavam essa condição. Dentre os pequenos municípios com menos de 20 mil habitantes, correspondentes a $69,2 \%$ do total de municípios brasileiros, menos da metade tinham legislação sobre zoneamento ou uso e ocupação do solo. Resta saber como os pequenos municípios que não possuíam esse tipo de legislação controlavam os modos de uso e ocupação do solo local. Muito provavelmente, simplesmente deixavam de exercer tal controle.

Diante desse quadro nacional composto por milhares de municípios com leis de zoneamento, surgem indagações a respeito do tipo e da qualidade de espaços e das formas urbanas geradas pelas aplicações dos parâmetros de uso e ocupação instituídos por essas leis. Quais são as características e qualidades desses espaços e formas urbanas, do ponto de vista da vitalidade e diversidade na vida urbana, geradas pelas aplicações daqueles parâmetros? Quais são os efeitos desses parâmetros nas formas de implantação das edificações nos lotes? Como as edificações, condicionadas pela aplicação dos parâmetros de uso e ocupação do solo, conformam as quadras urbanas e se relacionam com as calçadas e vias de acesso? Que tipo de vida urbana acontece nessas quadras e calçadas?

$\mathrm{O}$ presente artigo procura discutir alguns aspectos da Lei Geral de Zoneamento do Município de São Paulo de 1972 (Lei Municipal 7.805) (SÃO PAULO, 1972) e dos Planos Diretores Estratégicos do Município de São Paulo de 2002 (Lei Municipal 13.430) (SÃO PAULO, 2002) e 2014 (Lei Municipal 16.050) (SÃO PAULO, 2014) relacionados com mecanismos e parâmetros de regulação da ocupação do solo que geram formas urbanas.

Tabela 1 - Municípios Com Legislação Sobre Zoneamento ou Uso e Ocupação do Solo no Brasil - 2013

\begin{tabular}{|c|c|c|c|c|c|c|c|}
\hline \multirow[b]{2}{*}{ Faixas de Número de Habitantes } & \multirow{2}{*}{$\begin{array}{l}\text { Total de } \\
\text { Municípios }\end{array}$} & \multicolumn{6}{|c|}{ Legislação sobre Zoneamento ou Uso e Ocupação do Solo } \\
\hline & & $\begin{array}{l}\text { Com Legislação } \\
\text { Específica }\end{array}$ & $\%$ & $\begin{array}{l}\text { Como Parte Integrante do } \\
\text { Plano Diretor }\end{array}$ & $\%$ & Total & $\%$ \\
\hline Brasil & 5.570 & 1.742 & 31,3 & 1.279 & 23,0 & 3.021 & 54,2 \\
\hline Até 5.000 & 1.247 & 326 & 26,1 & 160 & 12,8 & 486 & 39,0 \\
\hline De 5.001 a 10.000 & 1.227 & 314 & 25,6 & 194 & 15,8 & 508 & 41,4 \\
\hline De 10.001 a 20.000 & 1.378 & 395 & 28,7 & 225 & 16,3 & 620 & 45,0 \\
\hline De 20.001 a 50.000 & 1.080 & 375 & 34,7 & 433 & 40,1 & 808 & 74,8 \\
\hline De 50.001 a 100.000 & 339 & 157 & 46,3 & 149 & 44,0 & 306 & 90,3 \\
\hline De 100.001 a 500.000 & 260 & 144 & 55,4 & 111 & 42,7 & 255 & 98,1 \\
\hline Mais de 500.000 & 39 & 31 & 79,5 & 7 & 17,9 & 38 & 97,4 \\
\hline
\end{tabular}

Fonte: Pesquisa de Informações Básicas Municipais IBGE, 2013 
As discussões sobre os parâmetros de regulação do parcelamento, uso e ocupação do solo na perspectiva da forma urbana não tem sido muito desenvolvida nos campos dos estudos urbanos brasileiros. Nesses campos, tais discussões enfatizam mais os efeitos daqueles parâmetros na valorização fundiária, na formação dos diferenciais de preço dos imóveis urbanos e rurais e na segregação socioespacial

Para discutir as relações entre a regulação territorial e a forma urbana, os conteúdos do presente artigo se organizam em três partes. Na primeira parte, subsequente a esta introdução, discutem-se os propósitos do "zoneamento convencional" em seus primórdios europeus e norte-americanos e a despreocupação em relação à qualidade das configurações espaciais geradas pela aplicação das normas e parâmetros de uso e ocupação do solo. Nessa parte aproveitam-se as críticas ao "zoneamento convencional" formuladas nos estudos elaborados por Emily Talen a partir do contexto das cidades norte-americanas.

$\mathrm{Na}$ segunda parte discutem-se alguns dos efeitos deletérios originários da despreocupação com a forma urbana que, de modo geral, percebe-se na utilização do "zoneamento convencional" no Plano Diretor Estratégico do Município de São Paulo instituído pela lei municipal 13.430/2002 e na Lei de Parcelamento, Uso e Ocupação do Solo 13.885/2004 (SÃO PAULO, 2004).

Na terceira parte discutem-se alguns parâmetros de uso e ocupação do solo que foram incluídos no novo Plano Diretor Estratégico do Município de São Paulo, instituído pela lei municipal 16.050/2014, e que demonstram clara intenção de gerar um tipo de forma urbana que promova maior vitalidade nos espaços urbanos paulistanos.

Nas considerações finais explicitam-se as principais contribuições do trabalho e aproveitam-se algumas iniciativas tomadas no processo em curso de revisão da Lei de Parcelamento, Uso e Ocupação do Município de São Paulo (lei municipal 13.885/2004) para discutir brevemente as intencionalidades relativas à forma urbana que foram incorporadas no projeto de lei 272/2015 (SÃO PAULO, 2015). Esse projeto de lei, em tramitação na Câmara Municipal de São Paulo, tem como objetivo rever aquela Lei de Parcelamento, Uso e Ocupação do Solo de 2004.

\section{Os Propósitos Iniciais do "Zoneamento Convencional"}

O "zoneamento convencional", discutido e praticado no Município de São Paulo ao longo de boa parte do século $\mathrm{XX}$, tem origens no "zoning" norte-americano. Em seu trabalho sobre a história do zoneamento paulistano, Feldman (2005) mostra a longa formulação desse instrumento de regulação urbana que, desde o início sofreu forte influência do zoneamento norte-americano. Segundo essa autora, "o zoneamento construído e praticado em São Paulo, a partir dos anos 1940, terá como referência explícita o modelo de zoneamento desenvolvido nos Estados Unidos" (FELDMAN, 2005, p. 114).

O zoneamento desenvolvido nos Estados Unidos, por sua vez, tem suas origens no pensamento de Reinhard Baumeister e Franz Adickes que foram, segundo Talen (2012), os primeiros a estabelecerem formalmente os fundamentos teóricos do zoneamento apresentados em encontro da Sociedade Alemã de Engenheiros e Arquitetos (Deutschen Architekten und Ingenieur Verein) que foi realizado em 1874. Calabi (2012) mostra que, nesse encontro, houve uma votação que expõe o seguinte:

Segundo as exigências, será necessário destinar determinadas ruas ou zonas inteiras da cidade para funções comerciais, industriais, residenciais etc. Além disso, será necessário prever a construção de edifícios públicos e deixar sem edificações áreas inteiras oportunamente escolhidas. Para a realização de tais reagrupamentos funcionais são necessários: localização adequada, meios de transporte apropriados, dimensões volumétricas convenientes, normas racionais para construções e uma regulamentação precisa das atividades industriais (CALABI, 2012, p. 127-128).

Tanto Talen (2012, p. 22) quanto Calabi (2012, p. 127) remetem as origens do zoneamento proposto por Baumeister ao decreto de Napoleão I de 1810 que dividiu a indústria em três classes e estabeleceu limites para zonas protegidas ("protected districts"). Talen (2012) ressalta que esse zoneamento napoleônico baseado em diferentes tipos de usos do solo foi o primeiro a aparecer. Após esse zoneamento baseado em diferenciações nos usos do solo foi criado o zoneamento definido a partir de diferentes modos de ocupação do solo e de volumes edificados. Nesse segundo tipo de zoneamento, a regulação dos modos de ocupação do solo ocorria a partir da aplicação de mecanismos definidos, de um lado, para as áreas da cidade mais consolidada e, de outro lado, para as áreas de subúrbio. De acordo com Calabi (2012, p. 128), tais mecanismos refletiam a "matriz higiênica do zoneamento" que buscava "assegurar ventilação e iluminação às habitações" a partir da "relação entre altura do edifício e a largura das ruas", de "pátios internos" e "casas individuais".

Conforme Calabi (2012, p. 129), Budapeste utilizou a técnica do zoneamento em 1874 servindo de exemplo para as primeiras experiências em cidades da Alemanha no final do século XIX. Para aquela autora, a cidade alemã de Dresden utilizou, em 1878, o primeiro plano de zoneamento baseado na redução progressiva da 
"possibilidade de aproveitamento construtivo do solo" (CALABI, 2012, p. 129). Calabi afirma que esse plano "prevê três zonas destinadas preferencialmente à construção de casarões, e exclui totalmente a indústria de um determinado setor da cidade" (Idem, p. 129). Afirma ainda que, após Dresden, outras cidades alemãs adotaram planos de zoneamento similares: Altona (1882), Darmstadt (1886) e Wroclaw (1887).

Berlin, com sérios problemas de insalubridades produzidos por processos desordenados e especulativos de urbanização, foi uma das primeiras cidades a instituir um zoneamento em 1892, segundo Calabi (2012, p. 128). Da Alemanha do final do século XIX, o zoneamento foi transposto para os Estados Unidos no início do século XX. Nova York foi a primeira cidade norte-americana a adotar, em 1916, um zoneamento abrangente que compreendia a área urbana como um todo.

Talen (2012) discute criticamente o "zoneamento convencional" a partir da experiência norte-americana. Ela faz essa discussão na perspectiva de uma visão teórica a respeito do bom e do mau urbanismo emitida logo no início do seu trabalho. De acordo com essa visão, o bom urbanismo é aquele que: (i) busca a forma urbana compacta e encoraja atividades realizadas por pedestres; (ii) minimiza a degradação ambiental; (iii) opõe-se à homogeneidade encorajando a diversidade social, econômica e de usos do solo; (iv) conecta usos e funções urbanas; (v) promove boa qualidade no domínio público de modo a provisionar oportunidades para a interação e intercâmbio; (vi) oferece acessos equitativos a bens, serviços e facilidades; (vii) protege a saúde e o ambiente humano. Já o mau urbanismo é aquele que se opõe àqueles aspectos gerando desconexões, dependência excessiva em relação ao uso do automóvel, desperdício de terras, degradação ambiental, uso monofuncional, homogeneidade, iniquidade, inacessibilidade e espaços e domínios públicos de baixa qualidade e mal projetados.

Ao avaliar os efeitos das normas urbanísticas no solo de cidades norte-americanas, Talen (2012) avalia o "zoneamento convencional" identificando-o, majoritariamente, com o mau urbanismo. Segundo a autora, os maus resultados espaciais gerados por esse "zoneamento convencional" advêm do abandono de um esforço consciente na indução de formas urbanas que qualifiquem positivamente os espaços e a vida urbana. Talen (2012) avalia que o abandono de tais esforços ocorreu em prol de objetivos que procuram favorecer e melhorar: o tráfego de veículos, a prevenção de incêndios, a saúde pública, a provisão de espaços para estacionamentos, dentre outros aspectos (TALEN, 2012, p. 128).

A autora afirma ainda que, no entanto, nem sempre foi assim, pois Edward M. Bassett, advogado tido como o pai do zoneamento americano ("Father of American Zoning") diretamente envolvido na formulação do zoneamento de Nova York instituído em 1916, tinha grande interesse no desenvolvimento físico da cidade. Ela explica que essa conexão explícita entre as regulações e a qualidade do lugar se perdeu (Idem: 10). A perda dessa conexão ocorreu apesar da necessidade de entender como a forma urbana é fortemente afetada pelas normas urbanísticas (Idem, p. 13).

Parcialmente sintonizada com o entendimento de Feldman (2005), Talen (2012) afirma que, no final do século XIX, muitos norte-americanos viam as normas urbanísticas como uma forma poderosa de proteção coletiva e comunitária contra o mercado capitalista (Idem, p. 20). Citando as regulações edilícias criadas por Frederick Law Olmsted junto com "Associates for Anchorage", aquela autora aponta para os propósitos subjacentes, de cunho excludente, presentes em normas urbanísticas que regulam custos mínimos de construção e exigem grandes recuos. Tais normas buscavam manter a área residencial socialmente homogênea, livre de intrusos e acessível somente pela população branca e com alto poder aquisitivo (Idem, p. 21).

Esses propósitos estavam também embutidos no "zoneamento convencional" que era usado, desde os seus primórdios norte-americanos, para proteger os subúrbios contra um adensamento excessivo. Envolto em uma onda de patriotismo cívico e de devoção à cidade, em geral de cunho populista, esse "zoneamento convencional" adquiriu um sentido alinhado com a ideia de que as comunidades deveriam ter o direito de proteger-se contra a poluição, a cobiça e a especulação imobiliária. Nessa perspectiva, o zoneamento era visto por muitos como a base da democracia e parte constitutiva de valores reais e permanentes e das aspirações sociais norte-americanas, principalmente aquelas relacionadas com a saúde e a segurança.

Nota-se que nessas expectativas depositadas sobre o "zoneamento convencional" há pouca ênfase em aspectos relacionados com a forma urbana. Apoiando-se em trabalho de Franco Mancuso (1978) sobre as experiências de "zoning", Feldman (2005) afirma que, nos primórdios do zoneamento paulistano,

"Zonas e tipologias de construções passam a diferenciarse e separar-se, e tornam-se a base para constituição de um plano de distribuição funcional. A terminologia passa, segundo o autor (Franco Mancuso), a ser a de 'plano de utilização do solo' ou 'plano de distribuição de superfícies', e as diferentes áreas da cidade - as zonas não mais se identificam por edifícios, praças, monumentos, ou por uma relação entre construções e áreas não edificadas, ou mesmo pelo projeto viário (...), mas única e exclusivamente pelas funções. A cidade 
passa a ser dividida em parcelas que se denominam pelas funções predominantes: comercial, residencial, industrial, consubstanciando um código que contém, em termos quantitativos, todos os elementos reguladores do uso e ocupação do solo" (FELDMAN, 2005, p. 121).

Em que pese essa primazia da função na formação e implementação do zoneamento paulistano, em detrimento de preocupações relativas a "tipologias de construções" e, em escalas mais amplas, a formas urbanas, os parâmetros de ocupação utilizados, no "zoneamento convencional" paulistano, produzem efeitos espaciais que são, em geral, deletérias. Tais efeitos precisam ser entendidos em profundidade, nos moldes do trabalho realizado por Talen (2012) a partir das legislações urbanísticas implementadas em cidades norte-americanas. No presente artigo destacam-se somente alguns desses efeitos de modo a deixar aberturas para a realização de estudos futuros.

No começo do século XXI o Município de São Paulo instituiu um Plano Diretor Estratégico (Lei Municipal 13.445/2002) e, após três décadas de vigência da Lei Geral de Zoneamento (Lei Municipal 7.805/1972)3, aprovou uma nova Lei de Parcelamento, Uso e Ocupação do Solo (Lei Municipal 13.885/2004) que, entretanto, manteve normas e parâmetros que reforçaram formas urbanas discutíveis. A seguir discutem-se algumas dessas formas.

\section{Padrões Discutíveis de Verticalização no Município de São Paulo}

A despreocupação do "zoneamento convencional" em relação à forma urbana presente na Lei Geral de Zoneamento do Município de São Paulo (Lei Municipal 7.805/1972) pode ter sido fruto da influência exercida pelo "zoning" norte-americano. Desde o início do século $\mathrm{XX}$, esse "zoning" serviu de referência para as discussões e proposições realizadas por engenheiros e arquitetos urbanistas radicados na cidade de São Paulo tais como, Francisco Prestes Maia, Anhaia Mello, Vitor da Silva Freire, João Florence D’Ulhoa Cintra, Carlos Lodi, dentre outros.

A implementação daquela Lei Geral de Zoneamento do Município de São Paulo (Lei Municipal 7.805/1972) foi responsável pela produção de formas urbanas que são bastante questionadas na atualidade por causa de seus efeitos negativos na vida urbana. Dentre essas formas destacam-se as mudanças nas tipologias das edificações verticais ocasionadas pelas inibições de usos mistos nos lotes. Tais inibições eliminam gradativamente a incorporação de estabelecimentos comerciais e de prestação de serviços em pavimentos térreos alinhados junto às calçadas e com moradias ou escritórios nos pavimentos superiores. Essas inibições ocorreram em favor da promoção de padrões de uso estritamente residencial ou comercial, com as edificações recuadas em relação às divisas frontais, laterais e de fundos, implantadas nos centros dos lotes e dissociadas das calçadas. Em muitas edificações essa dissociação se dá por meio de fechamentos e de "plataformas" formadas por pavimentos usados como garagens de veículos sobre os quais se implantam as torres de apartamentos ou de escritórios conformando, assim, o chamado "paliteiro". O efeito mais visível dessa forma de implantação de edificações nos espaços urbanos paulistanos é a perda de vitalidade gerada pela desertificação e rarefação de usos nas calçadas e nos espaços públicos.

Certamente, a vigência da Lei Geral de Zoneamento no Município de São Paulo (Lei Municipal 7.805/1972) ao longo de três décadas, com inúmeras alterações introduzidas nesse período, produziu outras formas urbanas questionáveis nos espaços urbanos paulistanos. Apesar de importante e necessária, a análise detalhada dessas formas urbanas geradas pelos parâmetros daquela Lei Geral de Zoneamento não cabe nos limites do presente artigo para o qual, entretanto, vale ressaltar somente as mudanças nas tipologias das edificações verticais.

Após um longo processo histórico bem analisado por Feldman (2005), a Lei Geral de Zoneamento de 1972 consolidou-se, a partir do Plano Diretor de Desenvolvimento Integrado (PDDI) de 1971, como um instrumento abrangente de regulação do uso e ocupação do solo urbano paulistano. Esses dois instrumentos de planejamento urbano foram elaborados sob a coordenação de Benjamin Adiron Ribeiro que foi funcionário da Prefeitura do Município de São Paulo e atuou no extinto Departamento de Urbanismo da Secretaria de Obras e, posteriormente, na Coordenadora Geral de Planejamento (COGEP).

A Lei Geral de Zoneamento do Município de São Paulo (Lei Municipal 7.805/1972) subdividiu a área urbana em vários tipos de zonas designadas por números e definidas a partir de um modelo ideal baseado em uma hierarquia de unidades urbanas polarizadas por centralidades comerciais e de prestação de serviços (demarcadas como Z3). Segundo o modelo ideal definido no PDDI, essas unidades tinham abrangências e áreas de influência que variavam desde escalas microlocais, de vizinhança, até regionais. A hierarquia dessas unidades urbanas deveria ser estruturada e interligada por uma rede regional de vias expressas que, no entanto, nunca foi executada. Essa rede de vias expressas também foi prevista por aquele PDDI de 1971 com base no Plano Urbanístico Básico (PUB) de 1968. 
Para cada uma daquelas zonas foram definidos parâmetros tradicionais para o controle da ocupação do solo como, por exemplo, exigências de recuos da edificação em relação às divisas dos lotes, taxas de ocupação das superfícies dos terrenos pela projeção horizontal das edificações, coeficientes de aproveitamento definidos a partir da relação entre as áreas dos lotes e as áreas construídas nesses lotes, gabaritos das edificações, dentre outros. Esses parâmetros, em si mesmos, já condicionam a geração de formas urbanas caracterizadas pela dissociação física entre as edificações e as ruas e calçadas, entre espaços públicos e privados.

Carvalho (2008) apontou, em sua dissertação de mestrado e na entrevista com Benjamin Adiron Ribeiro realizada em maio de 2015 (PESSOA, 2015), um dos efeitos dessas formas urbanas na cidade. $\mathrm{Na}$ correta avaliação daquele autor, essas formas urbanas desativa as interfaces entre os domínios privados e públicos nos contornos das quadras e inibe o desenvolvimento de usos mistos nos empreendimentos imobiliários. Com isso, os empreendimentos com estabelecimentos comerciais e de prestação de serviços instalados nos pavimentos térreos das edificações entram em extinção na produção imobiliária paulistana após a década de 1970. Nessas formas urbanas, tais pavimentos térreos são levados a se distanciarem das calçadas e das ruas e, com isso, criam dificuldades e bloqueios para o bom desempenho econômico daqueles estabelecimentos que se instalam em edificações com usos não residenciais.

Vale dizer que essa forma urbana indutora de usos monofuncionais é reiterada e agravada pela introdução da chamada "fórmula de Adiron"5 naquela Lei Geral de Zoneamento do Município de São Paulo (Lei Municipal 7.805/1972). Em linhas gerais, essa fórmula, definida por Benjamin Adiron Ribeiro em negociação com representantes de empresários que atuam no setor de incorporação imobiliária, possibilita o aumento do coeficiente de aproveitamento até o máximo de quatro vezes a área do terreno caso sejam adotadas reduções nas taxas de ocupação em empreendimentos imobiliários residenciais verticais multifamiliares. Assim, as fachadas desses empreendimentos tendem a se afastar ainda mais das divisas dos lotes, inclusive das calçadas e das ruas inibindo ainda mais os usos não residenciais nos pavimentos térreos e aprofundando as dissociações entre os domínios públicos e privados, mencionadas anteriormente.

O Plano Diretor Estratégico (PDE) instituído pela Lei Municipal 13.430/2002, e a Lei de Parcelamento, Uso e Ocupação do Solo (LPUOS) instituída pela Lei
Municipal 13.885/2004, manteve um modelo de regulação da ocupação do solo que gerou as mesmas formas urbanas resultantes da Lei Geral de Zoneamento de 1972 e relacionadas com a construção dos conhecidos prédios de apartamentos produzidos pelo mercado de incorporação. Além de favorecerem os interesses dos agentes do mercado de incorporação imobiliária, aquelas leis municipais contribuíram para a disseminação de formas urbanas problemáticas produzidas e reproduzidas nos empreendimentos imobiliários residenciais verticais disseminados no território urbano paulistano.

A aprovação do Plano Diretor Estratégico do Município de São Paulo (Lei Municipal 13.430/2002) introduziu versão atualizada da mencionada "formula de Adiron". O artigo 166 desse Plano trouxe uma fórmula matemática6 segundo a qual "o coeficiente de aproveitamento básico poderá ser beneficiado de acréscimo, limitado a 1 (um), sem o pagamento da contrapartida" (grifo dos autores) desde que o empreendedor utilize taxas de ocupação menores em seus empreendimentos imobiliários. Com o acréscimo no coeficiente de aproveitamento básico, esse empreendedor passou a pagar menos ou, em muitos casos, a deixar de pagar a contrapartida financeira correspondente à outorga onerosa do direito de construir.

Esse mecanismo foi responsável pela grande redução na arrecadação dessa contrapartida financeira pela Prefeitura do Município de São Paulo durante o período de grande aquecimento do mercado imobiliário ocorrido nas grandes cidades brasileiras, inclusive São Paulo, na segunda metade da década de 2000. A Figura 1 mostra as grandes áreas do Município de São Paulo onde os coeficientes de aproveitamento básicos 1 e 2 puderam ter acréscimos desde que a taxa de ocupação dos lotes fosse reduzida, reeditando as formas urbanas instauradas na Lei Geral de Zoneamento de 1972.

A Lei de Parcelamento, Uso e Ocupação do Solo (Lei Municipal 13.885/2004) simplesmente reitera aquele mecanismo no artigo 240, segundo o qual "fica mantido o incentivo à produção habitacional expresso nas disposições do artigo 166 do PDE para a categoria de uso R2v". Essa categoria de uso R2v refere-se aos empreendimentos imobiliários residenciais verticais multifamiliares. Ademais, o artigo 241 daquela Lei mantém o coeficiente de aproveitamento básico igual a 2 nas áreas indicadas no mapa da Figura 1, reduzindo as possibilidades de arrecadação de contrapartidas financeiras com a aplicação da outorga onerosa do direito de construir. Esses coeficientes básicos iguais a 2 já tinham sido estabelecidos pelo artigo 165 do Plano Diretor Estratégico (Lei Municipal 13.430/2002). 


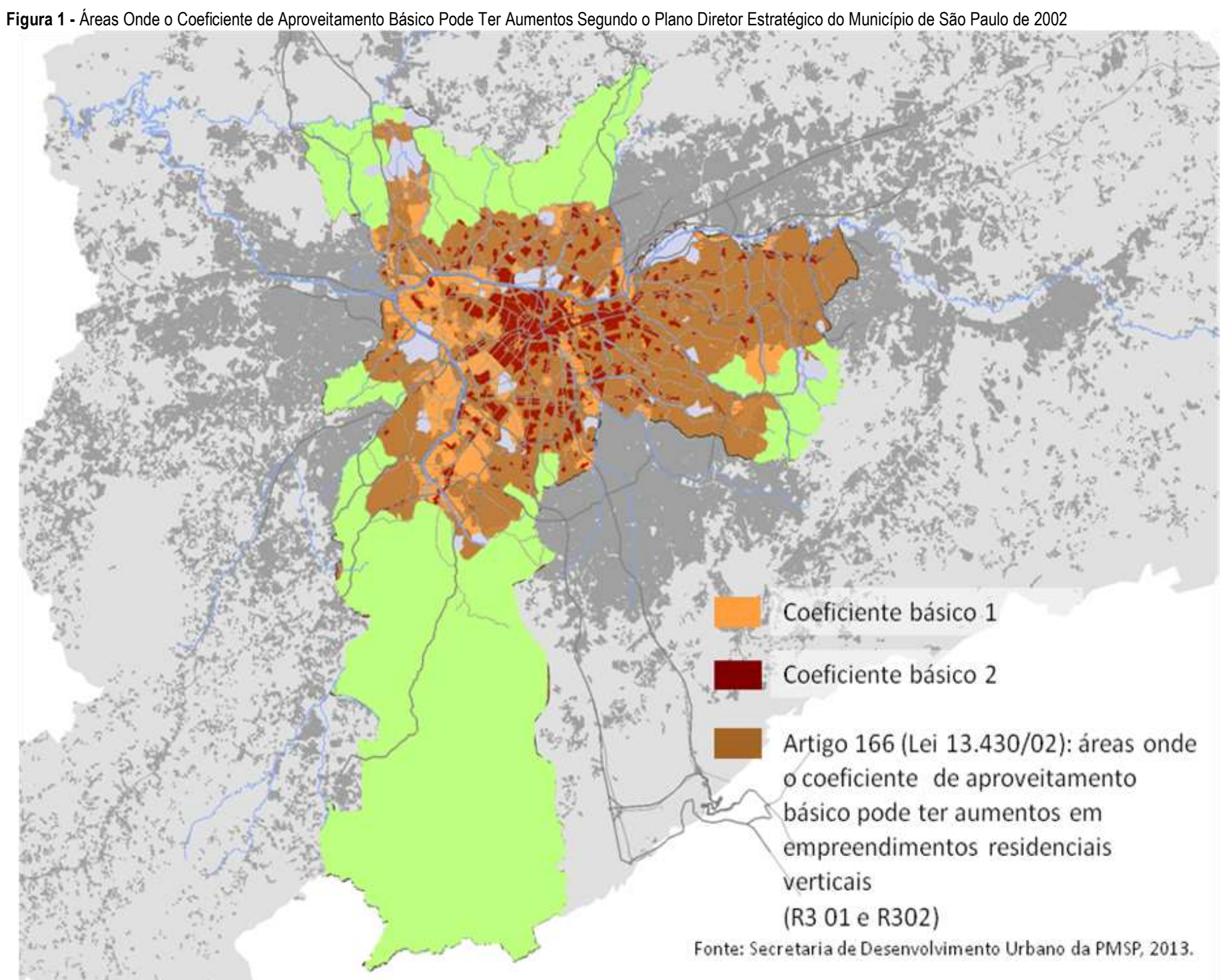

Fonte: Secretaria Municipal de Desenvolvimento Urbano da PMSP, 2013

O novo Plano Diretor Estratégico (PDE) do Município de São Paulo instituído pela Lei Municipal 16.050/2014, eliminou a "fórmula de Adiron" e todo aquele regramento para introduzir novos mecanismos $\mathrm{e}$ parâmetros de ocupação que buscam a geração de formas urbanas opostas àquelas descritas anteriormente e que são comentadas a seguir.

\section{A Retomada de Antigos Padrões de Verticalização no Município de São Paulo}

O Município de São Paulo foi um dos primeiros municípios brasileiros a elaborar e aprovar um Plano Diretor com base no Estatuto da Cidade. Trata-se do Plano Diretor Estratégico (PDE) aprovado em 2002 e instituído pela lei municipal 13.430. Esse PDE previa uma revisão em 2006 que foi apresentada pela Secretaria de Desenvolvimento Urbano da Prefeitura do Município de São Paulo e que foi fortemente rechaçada por diversos segmentos da sociedade civil paulistana.

Não faz parte dos objetivos deste artigo discutir detalhadamente todos os motivos que levaram a esse rechaço social e político à revisão do PDE do Município de São Paulo apresentada em 2006. Contudo, vale considerar um dos argumentos que foi largamente utilizado naquele rechaço. Trata-se de um argumento formulado em contexto marcado pelo aquecimento no mercado de incorporação imobiliária. Com esse aquecimento, tais empreendimentos passaram a ser construídos em diversos pontos da cidade de São Paulo localizados principalmente em bairros com moradias das camadas de renda média e alta. Com isso, altos prédios de apartamentos surgiram em ruas locais, em quadras formadas por residências térreas e assobradadas, provocando impactos negativos no tráfego de veículos, 
na paisagem urbana e, principalmente, na vida cotidiana dos bairros.

No calor dos debates e das declarações públicas, a produção daqueles empreendimentos imobiliários residenciais verticais foi identificada diretamente com a especulação imobiliária. Assim, a oposição à revisão do PDE de 2002 foi engrossada como uma oposição à produção daqueles empreendimentos imobiliários residenciais verticais vistos como destruidores da vida urbana em bairros residenciais, geradores de tráfego de automóveis particulares em vias locais e predadores do espaço urbano.

Essa carga crítica direcionada à produção daqueles empreendimentos gerou um contexto social mais favorável para se discutir regras de uso e ocupação do solo que tivesse maior incidência na produção imobiliária paulistana. Os representantes da sociedade civil que haviam se articulado em oposição à proposta de revisão do PDE, trazida ao público no período entre 2006 e 2010, colocavam-se bastante favoráveis à adoção de regras que definissem mais claramente os locais, os modos e os limites relativos àquela produção imobiliária.

Com nova revisão do PDE de 2002, realizada ao longo de 2013 e parte de 2014, definiram-se dois objetivos que foram incluídos no projeto de lei 688/2013 elaborado pelo Poder Executivo do Município de São Paulo como o novo PDE. Trata-se dos objetivos relativos ao "maior aproveitamento dos terrenos ao longo dos principais eixos de transporte coletivo com moradias e trabalho" e também com a intenção de "diminuir os impactos negativos dos empreendimentos e infraestruturas". Com a tramitação daquele projeto de lei na Câmara de Vereadores do Município de São Paulo tais objetivos foram reformulados de modo a diluir e obscurecer as intenções regulatórias incidentes sobre a produção imobiliária.

A despeito da diluição daquelas intenções regulatórias nos enunciados dos objetivos do novo PDE, instituído pela lei municipal 16.050 sancionada em 2014, a regulação do processo de urbanização e da produção imobiliária por meio de estratégias e mecanismos de ordenamento territorial, os quais já estavam presentes no projeto de lei $688 / 2013$, foram aprofundados em vários aspectos. Dentre tais estratégias e mecanismos é importante destacar aqueles que trazem preocupações manifestas em relação à geração de formas urbanas que, acredita-se, podem contribuir para melhorar a qualidade dos espaços urbanos, especialmente no que diz respeito às articulações entre os domínios públicos e privados.

Dentre os vários componentes do recém-instituído PDE do Município de São Paulo (Lei Municipal 16.050/2014), vale destacar os eixos de estruturação da transformação urbana, demarcados com base na rede estrutural de transporte coletivo, a partir dos quais se busca alterar os padrões da produção imobiliária promovida pela iniciativa privada. Esse destaque é importante para o presente artigo, pois dentre os objetivos desses eixos há um que declara explicitamente a intenção de gerar formas urbanas específicas. Nesse sentido, tal objetivo visa:

VIII - Orientar a produção imobiliária da iniciativa privada de modo a gerar:

a) diversificação nas formas de implantação das edificações nos lotes;

b) maior fruição pública nos térreos dos empreendimentos;

c) fachadas ativas no térreo dos edifícios;

d) ampliação das calçadas, dos espaços livres, das áreas verdes e permeáveis nos lotes;

e) convivência entre os espaços públicos e privados e entre usos residenciais e não residenciais; (lei municipal 16.050/2014, Artigo 23, Inciso VIII)

Para concretizar tais objetivos, o PDE de 2014 instituiu um conjunto de mecanismos que certamente irão influenciar a formatação dos novos empreendimentos imobiliários que serão implantados naqueles eixos de estruturação da transformação urbana, demarcados junto aos corredores de ônibus e no entorno de estações de trens e de metrô.

\section{Destinação de Áreas Privadas para Implantação de Espaços e Equipamentos Públicos}

Os empreendimentos a serem implantados em glebas e lotes com área superior a $40.000 \mathrm{~m}^{2}$, que não são obrigados a realizar o parcelamento do solo, deverão doar $20 \%$ dessa área para o poder público que deverá usar, no mínimo, $15 \%$ para implantar áreas verdes e o restante podendo ser utilizado para construir equipamentos públicos (lei municipal 16.050/2014, Artigo 79, parágrafo $\left.3^{\circ}, \mathrm{I}\right)$.

Essas áreas públicas doadas "deverão se localizar junto ao alinhamento da via e por ela ter acesso em nível" (Idem, alínea a) e poderão ser divididas em duas "áreas não contíguas, desde que nenhuma delas tenha área inferior a 5\% (cinco por cento) da área total" (Idem, alínea c).

Vale observar ainda que o órgão responsável pela aprovação daqueles empreendimentos "poderá exigir que uma parte da área a ser doada se destine a circulação de pedestres entre logradouros" (lei municipal 16.050/2014, Artigo 79, parágrafo $3^{\circ}$, II). 


\section{Desobstrução Entre Espaços Públicos e Privados}

Ainda naqueles empreendimentos implantados em glebas e lotes com área superior a $40.000 \mathrm{~m}^{2}$, "a vedação por muro não poderá exceder $25 \%$ (vinte e cinco por cento) da extensão das faces de quadra ou das testadas dos lotes" (Idem, IV). Essa exigência é interessante, pois busca desobstruir as relações entre os espaços públicos e privados e se contrapõe frontalmente à cultura dos muros que hoje é quase onipresente nos espaços urbanos paulistanos.

Com esse mecanismo busca-se reduzir o desconforto e a insegurança inerentes à experiência de caminhar e circular ao longo de grandes extensões de calçadas e ruas desertas ladeadas por altos muros opacos.

\section{Fruição Pública no Pavimento Térreo}

Outros mecanismos introduzidos no novo PDE do Município de São Paulo (Lei Municipal 16.050/2014) que deverão gerar novas formas urbanas nos eixos de estruturação da transformação urbana incidem nos empreendimentos a serem implantados em lotes com área superior a $5.000 \mathrm{~m}^{2}$ e inferior ou igual a $40.000 \mathrm{~m}^{2}$. Esses empreendimentos deverão, obrigatoriamente:

I - destinar para fruição pública área equivalente à no mínimo 20\% (vinte por cento) da área do lote, em espaço livre ou edificado, ao nível do passeio público ou no pavimento térreo;

II - observar taxa de permeabilidade de no mínimo $20 \%$ (vinte por cento) da área do lote;

III - observar limite de $25 \%$ (vinte e cinco por cento) de vedação da testada do lote com muros. (lei municipal 16.050/2014, artigo 79, parágrafo $4^{\circ}$ ).

É inegável a importância desses mecanismos que buscam aproveitar a produção imobiliária de iniciativa privada para melhorar a oferta de espaços públicos na cidade de São Paulo, aumentar a permeabilidade do solo urbano e reduzir a separação entre os domínios públicos e privados controlando os muros que cercam os lotes. Porém, é necessário complementar esses mecanismos com exigências que qualifiquem o uso cotidiano com a arborização e a instalação de assentos e mobiliários urbanos bem como promovam a gestão e a manutenção desses espaços privados de fruição pública. Mesmo porque o novo PDE definiu vantagens para os investidores que incorporarem áreas de fruição pública em seus empreendimentos. Conforme o artigo 82 desse PDE,

Quando uma parcela do lote for destinada à fruição pública, os potenciais construtivos básico e máximo do remanescente do lote serão calculados em função de sua área original, e não será cobrada outorga onerosa correspondente à metade do potencial construtivo máximo relativo à área destinada à fruição pública, desde que atendidas simultaneamente as seguintes condições:

I - a área destinada à fruição pública tenha no mínimo $250 \mathrm{~m}^{2}$ (duzentos e cinquenta metros quadrados) e esteja localizada junto ao alinhamento da via, ao nível do passeio público, sem fechamento e não ocupada por construções ou estacionamento de veículos;

II - a área destinada à fruição pública deverá permanecer permanentemente aberta;

III - a área destinada à fruição pública seja devidamente averbada em Cartório de Registro de Imóveis. (lei municipal 16.050/2014, artigo 82).

A ampliação da oferta de espaços bem qualificados para a fruição pública é bastante importante em uma cidade como São Paulo cujos espaços públicos perderam qualidade e foram reduzidos a meros resíduos retalhados por ruas e avenidas destinados exclusivamente à passagem de automóveis privados individuais. Essa oferta é mais importante ainda nos eixos de estruturação da transformação urbana propostos pelo novo PDE (Lei Municipal 16.050/2014), pois deverão receber maior densidade construtiva e populacional.

A geração de espaços para fruição pública a partir de empreendimentos imobiliários privados representa um avanço em relação ao PDE (Lei Municipal 13.430/2002) e à LPUOS (Lei Municipal 13.885/2004) anteriores que regulavam apenas a taxa de ocupação do edifício no lote e a taxa de permeabilidade, sem levar em consideração a oferta de espaços para fruição pública, arborizados ou não.

\section{Calçadas Mais Largas}

Vantagens foram instituídas também para os novos empreendimentos com frentes de lotes voltadas diretamente para as linhas de trem, metrô, monotrilho, veículos leve sobre trilhos (VLT), veículos leves sobre pneus (VLP) e para as linhas 1 azul e 3 vermelha do metrô. Nesses casos, empreendimentos que doarem partes frontais dos seus lotes para o alargamento de calçadas até a largura mínima de 5 metros serão dispensados "de recuo obrigatório de frente", terão os potenciais construtivos básico e máximo remanescentes do lote "calculados em função da área original" e não terão que pagar "outorga onerosa do direito de construir relativa ao potencial construtivo máximo correspondente à área doada" (Lei Municipal 16.050/2014, artigo 79, parágrafo $7^{\circ}$, I e II).

Terão vantagens similares os empreendimentos localizados nos eixos de estruturação da transformação urbana cujos lotes não possuem frentes voltadas para aquelas linhas de transporte coletivo de média e alta 
capacidade e que doarem áreas para o alargamento de calçadas até o mínimo de 3 metros (Idem, parágrafo $8^{\circ}$, I e II).

Esta medida vai ao encontro das análises de Gehl e Svarre (2013) e de Gehl (2013) sobre o comportamento humano nos espaços públicos das cidades europeias. Segundo esse autor, a qualidade da calçada está diretamente relacionada com a vontade das pessoas em caminharem e permanecerem nos lugares mais atrativos por serem seguros e confortáveis. A lei municipal 15.733/2013 (SÃO PAULO, 2013), conhecida como lei das calçadas, estabelece larguras mínimas para acomodar confortável e adequadamente as diversas atividades que acontecem no passeio público. A faixa de serviço próxima ao meio fio localizado junto à faixa de rolamento dos veículos deve ter no mínimo 0,70 metros e comportar todo tipo de mobiliário urbano. A faixa livre destinada à circulação de pedestres deve ter no mínimo 1,20 e estar livre de qualquer obstáculo. A faixa de acesso aos imóveis (onde devem ser alocadas as rampas de acesso a garagens, mobiliários móveis etc.) é dispensável se a calçada tiver a largura menor do que 3 metros.

Calçadas largas são importantes em locais com circulação e permanência de grande quantidade de pedestres como, por exemplo, em locais com altas densidades urbanas, eixos comerciais, pontos de embarque e desembarque de transportes coletivos.

\section{Limites Máximos em Vagas de Garagem e Estímulos a Fachadas Ativas}

A flexibilização na definição de áreas computáveis consideradas na aplicação dos coeficientes de aproveitamento foi utilizada como um mecanismo para coibir e induzir determinadas formas urbanas. De um lado, tal flexibilização foi utilizada para coibir o uso excessivo de área construída com vagas de garagem e, de outro lado, para estimular o uso do pavimento térreo com usos não residenciais acessíveis a partir do logradouro público e induzir usos mistos nos empreendimentos imobiliários, inclusive aqueles destinados à habitação de interesse social.

De acordo com o "caput" do artigo 80, inciso IV, da lei municipal 16.050/2014, não serão incluídas nas áreas computáveis consideradas nos cálculos para aplicação dos coeficientes de aproveitamento, "as áreas construídas no nível da rua com acesso direto ao logradouro, em lotes com testada superior a $20 \mathrm{~m}$ (vinte metros), até o limite de $50 \%$ (cinquenta por cento) da área do lote, destinadas a usos classificados nas subcategorias de usos nR1 e nR2”. Essas subcategorias se referem a usos não residenciais. Essa medida visa estimular o uso misto no lote, com atividades comerciais, institucionais e de prestação de serviços nos pavimentos térreos das edificações. Trata-se de um contraponto claro em relação às formas urbanas com usos monofuncionais $\mathrm{e}$ dissociados das calçadas e das vias vistas anteriormente.

Gehl (2013) afirma que o pedestre se relaciona e interage mais com o pavimento térreo e com os primeiros andares do edifício. Assim, quanto mais diversas forem as fachadas desse pavimento térreo, mais ricas serão as experiências dos pedestres. E quanto maior a permeabilidade visual através dessas fachadas, maior será a vitalidade nas ruas e calçadas, pois maior será a interação do caminhante com a cidade.

Naquele mesmo artigo 80 do novo PDE (Lei Municipal 16.050/2014), no inciso V do "caput", lê-se que "a área destinada aos usos não residenciais $\mathrm{nR}$, até o limite de $20 \%$ (vinte por cento) da área construída computável total do empreendimento, nos empreendimentos de uso misto e nos Empreendimentos de Habitação de Interesse Social - EHIS" também não será incluída na área computável para aplicação do coeficiente de aproveitamento.

De acordo com o parágrafo $2^{\circ}$ daquele artigo 80 , as vagas de estacionamento que ultrapassar os limites estabelecidos serão consideradas computáveis, "incluindo as áreas de circulação e manobra dessas vagas" (lei municipal 16.050/2014, artigo 80, parágrafo $2^{\circ}$ ). Com isso busca-se inibir a destinação de áreas construídas excessivamente grandes para garagens. Entende-se que isso representa desperdícios no aproveitamento de terras urbanas adequadas e bem localizadas, pois os usos dessas garagens se limitam a basicamente deixar um veículo parado durante parte ou na totalidade do dia e da noite. Tais limites são:

- para empreendimentos imobiliários residenciais: uma vaga por unidade habitacional;

- para empreendimentos imobiliários não residenciais: uma vaga para cada $70 \mathrm{~m}^{2}$ de área construída;

- para empreendimentos imobiliários de uso misto: uma vaga por unidade habitacional e uma vaga para cada $70 \mathrm{~m}^{2}$ de área construída não residencial.

Com todos esses mecanismos percebe-se que o novo PDE do Município de São Paulo (Lei Municipal 16.050/2014) busca concretizar, nos espaços urbanos localizados nos eixos de estruturação das transformações urbanas, demarcados junto aos sistemas de transporte coletivo, uma agenda urbana baseada:

- na articulação entre uso e ocupação do solo com o transporte coletivo;

- na limitação do uso de terras urbanas e de áreas construídas com vagas de estacionamento e, com 
isso, desestimular o uso excessivo do automóvel individual;

- na ampliação e melhoria na oferta de espaços públicos e calçadas;

- na mescla de usos residenciais e não residenciais de modo a favorecer a circulação a pé.

\section{Densidade Construtiva, Demográfica e Habitacional}

Faz parte daquela agenda urbana formulada para os eixos de estruturação da transformação urbana a adoção de mecanismos que promovam o adensamento urbano em suas dimensões construtivas e demográficas. Em várias passagens em que utiliza o termo densidade, o novo PDE do Município de São Paulo distingue, corretamente, aquelas duas dimensões da densidade urbana. A densidade construtiva nada mais é do que a quantidade de metros quadrados construídos em uma determinada unidade de área do solo urbano $\left(\mathrm{m}^{2} / \mathrm{hectare}\right)$. A densidade demográfica, mais conhecida e usual, é a quantidade de pessoas que habitam ou usam essa unidade de área (habitantes/hectare). Altos níveis de densidade construtiva não povoam necessariamente os espaços urbanos. Altos níveis de densidade demográfica podem sim promover o povoamento desses espaços7.

Nos eixos de estruturação da transformação urbana definidos no novo PDE do Município de São Paulo (Lei Municipal 16.050/2014), a provisão habitacional inserida nas novas formas urbanas a serem geradas pelos mecanismos descritos anteriormente deverá obedecer às determinações da "cota máxima de terreno por unidade habitacional". Esse parâmetro de ocupação do solo incide sobre a densidade habitacional a qual, por sua vez, se distingue da densidade construtiva e demográfica, pois diz respeito à quantidade de unidades habitacionais existentes em uma determinada unidade de área do solo urbano (habitações/hectare).

É interessante observar que a agenda urbana proposta para os eixos de estruturação da transformação urbana no novo PDE do Município de São Paulo possui forte sintonia com uma agenda urbana que está sendo colocada em prática em algumas cidades norte-americanas. Tratase da agenda operacionalizada pelo "zoneamento baseado na forma urbana" (form-based code), alinhado com o Novo Urbanismo (New Urbanism) que, por conseguinte, se alinha com as propostas de "cidades inteligentes" (Smart Cities) e do "urbanismo sustentável". Nesse começo de século XXI, o planejamento urbano e a regulação do uso e ocupação do solo em São Paulo continuam a mirar as experiências realizadas nos Estados Unidos.

\section{Considerações Finais}

Os planos diretores e as leis de uso e ocupação do solo, mais conhecidas como leis de zoneamento, ainda são os principais instrumentos de planejamento e regulação urbana e territorial utilizados nos municípios brasileiros, principalmente naqueles que possuem maiores portes populacionais. É chegada a hora de avaliar a qualidade desses instrumentos, especialmente na perspectiva da produção de formas urbanas as quais influenciam diretamente as vitalidades e as qualidades dos espaços das cidades.

Após o exame de alguns aspectos contidos na legislação urbanística do Município de São Paulo - Lei Geral de Zoneamento (Lei Municipal 7.805/1972), Lei de Parcelamento, Uso e Ocupação do Solo (Lei Municipal 13.885/2004) e Planos Diretores Estratégicos (Lei Municipal 13.430/2002) (Lei Municipal 16.050/2014) fica claro que o planejamento urbano paulistano precisa dar maior importância para as articulações entre os parâmetros de regulação do parcelamento, uso e ocupação do solo e as formas urbanas. Ao discutir os padrões de verticalização das edificações produzidas pelo mercado de incorporação, fica evidente a incidência daqueles parâmetros na geração de formas urbanas que podem ser mais ou menos deletérias para a vitalidade urbana, em especial nos espaços públicos. Tal constatação comprova o alcance e a importância do objetivo proposto para o presente artigo que esclarece, do ponto de vista da forma urbana, os sentidos de alguns mecanismos introduzidos no novo PDE do Município de São Paulo (Lei Municipal 16.050/2014).

A utilização de alguns mecanismos e parâmetros de ocupação do solo, bem como de instrumentos de política urbana como a outorga onerosa do direito de construir e o manejo das áreas computáveis e não computáveis na aplicação dos coeficientes de aproveitamento, busca induzir a geração de determinadas formas urbanas a partir da produção de empreendimentos imobiliários verticais.

Essa tendência é reforçada no novo PDE paulistano e na atual proposta de revisão da Lei de Parcelamento, Uso e Ocupação do Solo de 2004. Tal proposta encontra-se em tramitação na Câmara Municipal de São Paulo (Projeto de Lei 272/2015). Uma vez sancionada, essa proposta deverá ser objeto de análises sobre as relações entre os parâmetros de regulação territorial e a geração de formas urbanas. Tais análises irão complementar o presente artigo. Essa linha de estudos é certamente bastante frutífera e pode contribuir muitíssimo para melhorar a qualidade dos espaços urbanos da maior cidade brasileira. 


\section{Notas}

(1) Para conhecer detalhadamente os antecedentes históricos dessa Lei Geral de Zoneamento do Município de São Paulo aprovada no início da década de 1970 ver Feldman (2005).

(2) Entrevista publica no site Vitruvius no endereço eletrônico http://www.vitruvius.com.br/revistas/read/entrevista/16.062/5523 - consultado no dia 24/08/2015.

(3) Para conhecer os bastidores relativos à definição da "fórmula de Adiron" e seu detalhamento técnico, inseridos em um quadro geral da história do planejamento urbano desenvolvido pela Prefeitura do Município de São Paulo, ver a entrevista que Jorge Pessoa fez com Benjamin Adiron Ribeiro publicada no site Vitruvius (http://www.vitruvius.com.br/revistas/read/entrevista/16.062/5523 - consultado no dia 24/08/2015).

(4) Tal fórmula é a seguinte:

$\mathrm{CAu}=\mathrm{TO} / \mathrm{TOu} \times \mathrm{CAb}$

Onde: $\mathrm{CAu}=$ Coeficiente de Aproveitamento a ser utilizado

TOu = Taxa de Ocupação a ser utilizada

TO = Taxa de Ocupação Máxima admitida

$\mathrm{CAb}=$ Coeficiente de Aproveitamento Básico.

(5) Para maiores detalhes a respeito dos compassos e descompassos entre densidade construtiva e demográfica ver Nakano (2015).

\section{Referências}

CALABI, D. História do urbanismo europeu: questões, instrumentos, casos exemplares. Tradução: Marisa Barda e Anita Di Marco. São Paulo: Perspectiva, 2012.

CARVALHO, J. P. A tipologia dos edifícios de apartamentos e sua relação com o tecido urbano da cidade: um estudo de suas transformações nos últimos 40 anos. 2008. 224 p. Dissertação (Mestrado em Planejamento Urbano e Regional) - Faculdade de Arquitetura e Urbanismo, Universidade de São Paulo, São Paulo.

PESSOA, Jorge. Entrevista com Benjamin Adiron Ribeiro. Entrevista, São Paulo, ano 16, n. 062.02, Vitruvius, mai. 2015. Disponível em: <http://www.vitruvius.com.br/revistas/read/entrevista/16.062/5523>.

FELDMAN, Sarah. Planejamento e zoneamento: São Paulo 1947 1972. São Paulo: EDUSP, 2005.

GEHL, J.; SVARRE, B. How to study public life. Washington/Covelo/London: Island Press, 2013.

GEHL, J. Cidades para pessoas. Tradução: Anita Di Marco. 2 ed. São Paulo: Perspectiva, 2013.

IBGE INSTITUTO BRASILEIRO DE GEOGRAFIA E ESTATÍSTICA. Pesquisa de informações básicas municipais: Perfil dos Municípios Brasileiros 2013. Rio de Janeiro: IBGE, 2014. Disponível em:

<ftp://ftp.ibge.gov.br/Perfil_Municipios/2013/munic2013.pdf>. Acesso em: 10 fev. 2016.

SÃO PAULO (Município). Lei n ${ }^{\circ} 7.805$, de 1 de novembro de 1972. Dispõe sobre o parcelamento, uso e ocupação do solo do Município, e dá outras providências. Diário Oficial do Município de São Paulo. São Paulo, SP, 3 nov. 1972.

SÃO PAULO (Município). Lei n. 13.430, de 13 de setembro de 2002. Institui o Plano Diretor Estratégico do Município de São Paulo. Diário Oficial do Município de São Paulo, São Paulo, 14 set. 2002.

SÃO PAULO (Município). Lei n. 13.885, de 25 de agosto de 2004. Estabelece normas complementares ao Plano Diretor Estratégico, institui os Planos Regionais Estratégicos das Subprefeituras, dispõe sobre o parcelamento, disciplina e ordena o Uso e Ocupação do Solo do Município de São Paulo. Diário Oficial do Município de São Paulo, São Paulo, 6 out. 2004.

SÃO PAULO (Município). Lei n. 15.733, de 3 de maio de 2013. Introduz alterações na lei 15.442, de 9 de setembro de 2011, bem como torna sem efeito multas aplicadas, conforme especifica. Diário Oficial do Município de São Paulo, São Paulo, 4 mai. 2013. 
SÃO PAULO (Município). Lei n. 16.050, de 31 de julho de 2014. Aprova a política de desenvolvimento urbano e o Plano Diretor Estratégico do Município de São Paulo e revoga a lei 13.430/2002. Diário Oficial do Município de São Paulo, São Paulo, 1 ago. 2014.

SÃO PAULO (Município). Projeto de Lei n. 272, de 2 de junho de 2015. Disciplina o parcelamento, o uso e a ocupação do Município de São Paulo, de acordo com a lei 16.050, de 31 de julho de 2014. Câmara Municipal de São Paulo. Disponível em: <http://www.radarmunicipal.com.br/proposicoes/projeto-de-lei-272-2015>. Acesso em: 10 fev. 2016.

NAKANO, A. K. Elementos demográficos sobre a densidade urbana da produção imobiliária: São Paulo, uma cidade oca? 2015. 348 f. Tese (Doutorado em Demografia) - Núcleo de Estudos de População, Instituto de Filosofia e Ciências Humanas, Universidade de Campinas, Campinas.

TALEN, E. City rules: how regulations affect urban form. Washington/Covelo/London: Island Press, 2012.

\section{${ }^{1}$ Kazuo Nakano}

Arquiteto Urbanista. Doutor em Demografia. Rua Alves Guimarães, 461, Apartamento 112, São Paulo/SP, Brasil, CEP 05410-00

\section{${ }^{2}$ Sully Alonso Guatella}

Arquiteta Urbanista. Mestranda em Projeto, Produção e Gestão do Espaço Urbano. Alameda Maruás, 232, São Paulo/SP, Brasil, CEP 04068-110 